\title{
Efeito do porta-enxerto na qualidade do cacho da videira 'Niágara Rosada'(1)
}

\author{
Dário Pauletto ${ }^{(2)}$, Francisco de Assis Alves Mourão Filho( ${ }^{(3)}$, Ricardo Alfredo Kluge ${ }^{(4)}$ \\ e João Alexio Scarpare Filho( ${ }^{(5)}$
}

\begin{abstract}
Resumo - O objetivo deste trabalho foi avaliar a qualidade do cacho da videira 'Niágara Rosada' (Vitis labrusca L.) enxertada sobre cinco porta-enxertos e avaliada durante sete safras na região de Taubaté, SP. Os cachos colhidos nas plantas enxertadas sobre 'IAC 313', 'IAC 766' e 'Traviú' apresentaram tamanho (comprimento e largura), massa e número de bagas significativamente maiores do que o verificado nas plantas enxertadas sobre 'Kober 5BB' e 'Schwarzmann'. A baga apresentou massa significativamente maior no 'IAC 766' e 'Traviú' em comparação ao 'Schwarzmann'. O teor de sólidos solúveis dos frutos foi maior no 'Kober 5BB' $\left(15,46^{\circ}\right.$ Brix $)$ e 'Schwarzmann' $\left(15,28^{\circ}\right.$ Brix $)$ em comparação ao verificado no 'IAC 313 ' (14,18 ${ }^{\circ}$ Brix $)$.
\end{abstract}

Termos para indexação: Vitis labrusca, uva, propagação, enxertia.

\section{Effect of rootstock on cluster quality of 'Niágara Rosada' table grape}

\begin{abstract}
The aim of this paper was to evaluate the cluster quality of 'Niágara Rosada' table grape (Vitis labrusca L.) grafted on different rootstocks and evaluated during seven crops, at Taubaté, SP, Brazil. The clusters harvested in plants grafted with 'IAC 313', 'IAC 766' and 'Traviú' presented size (length and width), mass and number of berries significantly higher than those verified in plants grafted with 'Kober 5BB' and 'Schwarzmann'. The berry presented mass significantly higher in the 'IAC 766' and 'Traviú' if compared to the 'Schwarzmann'. Fruit soluble solid content was higher in 'Kober 5BB' $\left(15.46^{\circ}\right.$ Brix $)$ and 'Schwarzmann' $\left(15.28^{\circ}\right.$ Brix $)$ if compared to the 'IAC $313^{\prime}$ (14.18 ${ }^{\circ}$ Brix $)$.
\end{abstract}

Index terms: Vitis labrusca, grapes, propagation, grafting.

\section{Introdução}

As condições fundamentais de um bom porta-enxerto exigidas na viticultura incluem resistência a filoxera e nematóides, adaptação ao meio ambiente, facilidade de propagação, afinidade satisfatória com as cultivares copa, sanidade e desenvolvimento, de acordo com o destino da produção (Hidalgo, 1993).

O porta-enxerto influencia o crescimento vegetativo, a produção e a qualidade do cacho da

\footnotetext{
(1) Aceito para publicação em 25 de setembro de 2000. Parcialmente financiado pela FAPESP, SP.

${ }^{(2)}$ Escola Superior de Agricultura Luiz de Queiroz (ESALQ), Dep. de Produção Vegetal, Caixa Postal 9, CEP 13418-900 Piracicaba, SP. Bolsista da FAPESP.

${ }^{(3)}$ ESALQ, Dep. de Produção Vegetal. Bolsista do CNPq E-mail: famourao@esalq.usp.br

(4)ESALQ, Dep. de Ciências Biológicas.

${ }^{(5)}$ ESALQ, Dep. de Produção Vegetal.
}

videira; sofre grande interferência edafoclimática, e responde diferentemente de acordo com a copa sobre ele enxertada (Hartmann \& Kester, 1990). Atualmente, um número extenso de porta-enxertos encontra-se disponível aos produtores; porém, cada um deles apresenta suas vantagens e deficiências. Apenas com a experimentação agrícola pode-se determinar com regular precisão qual o mais adequado para uma determinada cultivar e região (Pommer et al., 1997).

Martins et al. (1981) estudaram o comportamento da cultivar de uva de mesa Patrícia (IAC 871-41) sobre os porta-enxertos 'Traviú', 'RR 101-14', 'Kober 5BB', 'IAC 313', 'IAC 766', no período de 1975 a 1980, em Jundiaí, SP. Verificaram que as maiores produções foram obtidas no 'IAC 766' e 'Traviú', seguidos pelo 'IAC 313' e '101-14'; o 'Kober 5BB' apresentou a menor produção. Não foram notadas diferenças significativas na concentração de sólidos solúveis nos frutos dos diferentes tratamentos. 
Terra et al. (1987) investigaram a influência dos porta-enxertos 'Golia', 'Traviú', 'Schwarzmann', 'IAC 571-6', 'IAC 572' e 'IAC 766' sobre a produção e qualidade dos frutos de videiras 'Niágara Rosada', durante o período de 1975 a 1983, em Jundiaí, SP. Os autores não observaram efeito do porta-enxerto sobre a massa dos cacho, que variou de 168 a $179 \mathrm{~g}$. Quanto ao teor de sólidos solúveis, o portaenxerto 'Schwarzmann' provocou maior acúmulo $\left(15,32^{\circ} \mathrm{Brix}\right)$ em comparação ao 'Traviú' $\left(14,85^{\circ}\right.$ Brix).

Avaliando as cultivares de uva branca para vinho IAC 116-31 e IAC 960-12 enxertadas sobre cinco porta-enxertos, Pires et al. (1989) acompanharam a produção de três anos sucessivos na região de Jundiaí. Constataram que o 'IAC 766' e o 'Traviú' apresentaram melhor desempenho que o 'IAC 313', o 'RR 101-14' e o 'Kober 5BB'. Quanto ao teor de sólidos solúveis totais, não observaram diferenças em função do porta-enxerto.

Terra et al. (1989), em Jundiaí, estudaram o comportamento de duas cultivares de uva tipo moscatel para vinho (IAC 21-14 e IAC 931-13) em diferentes porta-enxertos ('RR 101-14', 'Kober 5BB', 'Traviú', 'IAC 313' e 'IAC 766'). Os autores averiguaram que as maiores médias de produção para a cultivar IAC 21-14 foram obtidas sobre 'IAC 766' ' 'Traviú', seguidos do 'RR 101-14' e 'IAC 313'. O teor de sólidos solúveis das duas cultivares não foi influenciado pelo porta-enxerto.

O Vale do Paraíba, no Estado de São Paulo, é uma região onde as condições edafoclimáticas favorecem a prática de viticultura, desde que sejam selecionadas para essa região as cultivares copa e portaenxertos ideais.

O objetivo deste trabalho foi avaliar os efeitos de cinco porta-enxertos sobre as características do cacho de videira 'Niágara Rosada', estabelecidas em Taubaté, SP.

\section{Material e Métodos}

O presente trabalho foi conduzido na área experimental do Departamento de Ciências Agrárias da Universidade de Taubaté (UNITAU), no Município de Taubaté, no Vale do Paraíba, SP, localizado à latitude $22^{\circ} 54^{\prime}$ e longitude $45^{\circ} 33^{\prime}$. A altitude do local é de 600 metros. O clima da região, segundo a classificação de Köppen, é do tipo
Cwa: tropical de altitude, com inverno seco e chuvas de verão. A média pluviométrica da região varia de $1.000 \mathrm{a}$ $1.500 \mathrm{~mm} / \mathrm{ano}$; a temperatura média é de $22^{\circ} \mathrm{C}$, e a umidade relativa é de $78 \%$, em média.

O solo do local do experimento é classificado como Latossolo Vermelho-Amarelo álico (Typic Hapludox), fase terraço, série Ipiranga, com textura média argilosa.

Para a formação das mudas, estacas com aproximadamente $45 \mathrm{~cm}$ de comprimento e $1 \mathrm{~cm}$ de diâmetro foram coletadas em julho de 1988 e plantadas em sacos de polietileno contendo o substrato terra de subsolo e esterco de curral curtido (1:1). Em novembro do mesmo ano foi realizado o plantio das estacas no campo, no espaçamento $2,0 \mathrm{~m} \times 1,5 \mathrm{~m}$. A enxertia da cultivar copa foi efetuada em julho de 1989, utilizando-se o processo de garfagem em fenda cheia.

O vinhedo foi conduzido no sistema de espaldeira com três fios de arame e regime de poda curta em duas gemas (gema da coroa e primeira gema). A poda foi realizada sempre na primeira semana de agosto. Logo após a poda, foi aplicada cianamida hidrogenada (Dormex a 5,0\% do produto comercial), sendo efetuada irrigação antes e após a poda. A desbrota foi realizada semanalmente, a partir do início de setembro até novembro. A correção do solo e as adubações foram feitas de acordo com a análise do solo, e os tratamentos fitossanitários (aplicação de fungicidas e inseticidas) foram realizados sempre que necessário. Os demais tratos culturais foram realizados segundo as recomendações técnicas da cultura.

Foram utilizados cinco porta-enxertos, tendo como cultivar copa a videira 'Niágara Rosada' (Vitis labrusca L.). Os porta-enxertos utilizados foram 'IAC 313' ('Tropical'), 'IAC 766' ('Campinas'), 'Kober 5BB', 'Traviú' ('Ripária do Traviú') e 'Schwarzmann'. As características destes porta-enxertos estão descritas em Pommer et al. (1997).

O delineamento experimental adotado foi o quadrado latino de cinco linhas e cinco colunas, com cinco repetições e seis plantas por parcela.

As seguintes determinações foram realizadas durante sete safras (91/92 a 97/98): a) tamanho (comprimento e largura em $\mathrm{cm}$ ) e massa (g) do cacho avaliados em três cachos por parcela, escolhidos ao acaso; b) número de bagas por cacho contado em três cachos por parcela; c) massa (g) das bagas retiradas de três cachos por parcela e pesadas; a massa média da baga foi determinada dividindo-se a massa total pelo número de bagas presentes nos cachos; d) teor de sólidos solúveis totais ( ${ }^{\circ}$ Brix), determinado por refratômetro de mão e proveniente do suco das bagas de três cachos por parcela.

Os dados coletados foram submetidos à análise de variância (teste F), e, em caso de significância, efetuou-se a comparação múltipla de médias pelo teste de Tukey a 5\% de probabilidade. 


\section{Resultados e Discussão}

Os cachos obtidos nas plantas enxertadas com 'IAC 313', 'IAC 766', e 'Traviú' apresentaram tamanho e massa significativamente maior do que o verificado no 'Kober 5BB' e no 'Schwarzmann', na média geral do experimento (Tabela 1). Estes resultados diferem daqueles obtidos por Terra et al. (1987), que não observaram diferença para a massa do cacho de videira 'Niágara Rosada' sobre os porta-enxertos 'IAC 766', 'Traviú', 'Schwarzmann', 'IAC 572' e 'IAC 571-6', na região de Jundiaí, SP.
Quanto ao número de bagas por cacho (Tabela 2), também verificou-se superioridade do 'IAC 313'e 'IAC 766' e 'Traviú' em relação ao 'Kober 5BB' e ao 'Schwarzmann', na média do experimento. $\mathrm{O}$ menor número de frutos no 'Kober 5BB' e 'Schwarzmann' pode explicar, em parte, a menor massa do cacho obtida nestes porta-enxertos.

A massa média das bagas observada no 'IAC 766' e 'Traviú' foi significativamente maior em relação à observada no 'Schwarzmann', mas não diferiu do 'Kober 5BB' e do 'IAC 313', na média do experimento (Tabela 2).

Tabela 1. Comprimento, largura e massa do cacho em videira 'Niágara Rosada' sobre diferentes porta-enxertos. Taubaté, SP, 1991-1997(1).

\begin{tabular}{|c|c|c|c|c|c|c|c|c|}
\hline \multirow[t]{2}{*}{ Porta-enxerto } & \multicolumn{7}{|c|}{ Safra } & \multirow[t]{2}{*}{ Média } \\
\hline & $91 / 92$ & $92 / 93$ & $93 / 94$ & $94 / 95$ & $95 / 96$ & $96 / 97$ & $97 / 98$ & \\
\hline & \multicolumn{8}{|c|}{ Comprimento do cacho $(\mathrm{cm})$} \\
\hline 'IAC 313' & $12,82 \mathrm{ab}$ & $11,54 \mathrm{a}$ & $13,33 \mathrm{a}$ & 9,54 & 11,04 & $9,41 \mathrm{a}$ & $12,97 \mathrm{a}$ & $11,52 \mathrm{a}$ \\
\hline 'IAC 766' & $12,98 \mathrm{ab}$ & $11,54 \mathrm{a}$ & $14,07 \mathrm{a}$ & 8,97 & 10,83 & $10,09 \mathrm{a}$ & $11,96 \mathrm{ab}$ & $11,49 \mathrm{a}$ \\
\hline 'Kober 5BB' & $10,15 b$ & $9,47 b$ & $11,07 \mathrm{~b}$ & 7,10 & 9,64 & $7,28 \mathrm{~b}$ & $11,51 \mathrm{ab}$ & $9,49 b$ \\
\hline ‘Traviú' & $13,25 \mathrm{a}$ & $11,42 \mathrm{a}$ & $13,37 \mathrm{a}$ & 9,00 & 11,03 & $9,43 \mathrm{a}$ & $10,61 b$ & $11,16 \mathrm{a}$ \\
\hline 'Schwarzmann' & $10,05 b$ & $10,97 \mathrm{ab}$ & $13,20 \mathrm{a}$ & 8,67 & 9,80 & $6,29 b$ & $10,06 \mathrm{~b}$ & $9,86 \mathrm{~b}$ \\
\hline $\mathrm{F}$ (tratamentos) & $4,18^{*}$ & $3,99^{*}$ & $4,69^{*}$ & $2,21^{\mathrm{ns}}$ & $0,63^{\text {ns }}$ & $9,74^{* *}$ & $4,36^{*}$ & $7,83^{* *}$ \\
\hline d.m.s. & 2,96 & 1,65 & 1,97 & - & - & 1,96 & 2,05 & 1,29 \\
\hline \multirow[t]{2}{*}{ C.V. $(\%)$} & 14,82 & 8,94 & 9,02 & 16,03 & 16,92 & 13,72 & 10,68 & 7,15 \\
\hline & \multicolumn{8}{|c|}{ Largura do cacho $(\mathrm{cm})$} \\
\hline 'IAC 313' & $6,55 \mathrm{a}$ & 5,89 & $6,53 \mathrm{a}$ & 6,01 & 7,33 & $6,41 \mathrm{a}$ & $6,17 \mathrm{a}$ & $6,41 \mathrm{a}$ \\
\hline 'IAC 766’ & $6,82 \mathrm{a}$ & 6,17 & $6,73 \mathrm{a}$ & 5,97 & 7,95 & $6,54 \mathrm{a}$ & $6,53 \mathrm{a}$ & $6,67 \mathrm{a}$ \\
\hline 'Kober 5BB' & $5,51 \mathrm{ab}$ & 5,54 & $5,80 \mathrm{~b}$ & 4,43 & 7,09 & $5,33 b$ & $5,10 \mathrm{bc}$ & $5,54 b$ \\
\hline 'Traviú' & $5,91 \mathrm{ab}$ & 6,19 & $6,57 \mathrm{a}$ & 5,43 & 6,77 & $6,49 a$ & $5,45 b$ & $6,12 \mathrm{a}$ \\
\hline 'Schwarzmann' & $5,14 \mathrm{~b}$ & 6,05 & $5,80 \mathrm{~b}$ & 5,04 & 6,90 & $4,96 \mathrm{~b}$ & $4,91 \mathrm{c}$ & $5,54 \mathrm{~b}$ \\
\hline $\mathrm{F}$ (tratamentos) & $3,48^{*}$ & $2,35^{\mathrm{ns}}$ & $18,52^{* *}$ & $2,71^{\mathrm{ns}}$ & $0,39^{\mathrm{ns}}$ & $8,00^{* *}$ & $25,09^{* *}$ & $9,29^{* *}$ \\
\hline d.m.s & 1,41 & - & 0,39 & - & - & 0,99 & 0,52 & 0,58 \\
\hline \multirow[t]{2}{*}{ C.V. (\%) } & 14,03 & 6,56 & 3,73 & 16,72 & 10,82 & 9,88 & 5,50 & 5,74 \\
\hline & \multicolumn{8}{|c|}{ Massa do cacho (g) } \\
\hline 'IAC 313' & $220,55 a$ & $167,00 \mathrm{a}$ & $228,40 a$ & $103,60 \mathrm{a}$ & 162,60 & $162,23 \mathrm{a}$ & $209,97 \mathrm{ab}$ & $179,19 \mathrm{a}$ \\
\hline 'IAC 766’' & $213,40 \mathrm{a}$ & $189,80 \mathrm{a}$ & $269,40 \mathrm{a}$ & $94,20 \mathrm{ab}$ & 177,80 & $188,86 a$ & $232,46 a$ & $195,13 \mathrm{a}$ \\
\hline 'Kober 5BB' & $122,00 \mathrm{~b}$ & $121,80 \mathrm{~b}$ & $179,60 \mathrm{~b}$ & $51,00 \mathrm{~b}$ & 130,40 & $98,60 \mathrm{~b}$ & $160,15 c$ & $123,36 b$ \\
\hline 'Traviú' & $188,80 \mathrm{ab}$ & $170,20 \mathrm{a}$ & $244,60 \mathrm{a}$ & $104,00 \mathrm{a}$ & 138,60 & $166,86 \mathrm{a}$ & $164,49 b c$ & $168,22 \mathrm{a}$ \\
\hline 'Schwarzmann' & $112,80 \mathrm{~b}$ & $173,60 \mathrm{a}$ & $228,20 \mathrm{a}$ & $83,00 \mathrm{ab}$ & 109,60 & $62,89 b$ & $135,56 \mathrm{c}$ & $129,38 b$ \\
\hline $\mathrm{F}$ (tratamentos) & $6,25^{* * *}$ & $4,83^{*}$ & $6,01^{* * *}$ & $3,53^{*}$ & $2,03^{\mathrm{ns}}$ & $9,82^{* *}$ & $10,01^{\text {*** }}$ & $13,66^{* * *}$ \\
\hline d.m.s. & 76,71 & 43,58 & 50,46 & 43,99 & - & 63,59 & 47,11 & 32,03 \\
\hline C.V. $(\%)$ & 26,53 & 15,72 & 13,01 & 29,94 & 29,27 & 27,76 & 15,48 & 11,95 \\
\hline
\end{tabular}


Na avaliação do teor de sólidos solúveis dos frutos, poucas diferenças foram encontradas ao longo das safras avaliadas mas, na média geral, constatouse que os frutos colhidos sobre o 'Kober 5BB' e 'Schwarzmann' apresentaram maior teor de sólidos solúveis do que os obtidos sobre o 'IAC 313' (Tabela 2). Embora muitos autores não tenham verificado interferência do porta-enxerto sobre o teor de sólidos solúveis dos frutos (Martins et al., 1981; Pires et al., 1989; Terra et al., 1989), Ruhl et al. (1988) afirmaram que há diferença neste teor, em razão da combinação copa/porta-enxerto, do nível de produção, e o do clima da região. Gonçalves (1996) constatou que o porta-enxerto 'IAC 313' promoveu o menor teor de sólidos solúveis na cultivar
Folha de Figo, embora esse porta-enxerto tenha sido o mais produtivo da região de Caldas (MG). Terra et al. (1989) verificaram que o 'Schwarzmann' promoveu maior ${ }^{\circ} \mathrm{Brix}$, tendo sido também o mais produtivo para a 'Niágara Rosada' em Jundiaí, SP.

As variações encontradas para as características do cacho da videira 'Niágara Rosada' em diferentes porta-enxertos estão relacionadas com as interações que as combinações copa/porta-enxerto proporcionaram. Tem sido considerado que tais interações são decorrentes de um equilíbrio fisiológico ou grau de afinidade, o qual influencia o crescimento e a produção de uma determinada combinação (Zuluaga, 1943; Gonçalves, 1996). Este equilíbrio, de acordo com Hartmann \& Kester (1990), é resultante de mecanis-

Tabela 2. Número de bagas por cacho, massa da baga e teor de sólidos solúveis ( ${ }^{\circ}$ Brix) em videira 'Niágara Rosada' sobre diferentes porta-enxertos. Taubaté, SP, 1991-1997(1).

\begin{tabular}{|c|c|c|c|c|c|c|c|c|}
\hline \multirow[t]{2}{*}{ Porta-enxerto } & \multicolumn{7}{|c|}{ Safra } & \multirow[t]{2}{*}{ Média } \\
\hline & 91/92 & $92 / 93$ & 93/94 & 94/95 & 95/96 & 96/97 & 97/98 & \\
\hline & \multicolumn{8}{|c|}{ Número de bagas por cacho } \\
\hline 'IAC 313' & $56,60 \mathrm{a}$ & $43,20 \mathrm{a}$ & 56,20 & $28,20 \mathrm{a}$ & 39,80 & $33,93 \mathrm{a}$ & $52,00 \mathrm{a}$ & $44,28 \mathrm{a}$ \\
\hline 'IAC 766’ & $48,40 \mathrm{a}$ & $45,20 \mathrm{a}$ & 60,80 & $24,00 \mathrm{ab}$ & 44,00 & $37,00 \mathrm{a}$ & $51,80 \mathrm{a}$ & $44,46 a$ \\
\hline 'Kober 5BB' & $32,80 \mathrm{~b}$ & $32,20 \mathrm{~b}$ & 43,80 & $15,60 \mathrm{~b}$ & 32,40 & $21,67 b$ & $39,67 b$ & $31,16 \mathrm{~b}$ \\
\hline ‘Traviú’ & $61,00 \mathrm{a}$ & $42,40 \mathrm{a}$ & 59,80 & $26,20 \mathrm{a}$ & 36,60 & $32,47 \mathrm{a}$ & $39,07 \mathrm{~b}$ & $42,59 a$ \\
\hline 'Schwarzmann' & $29,60 \mathrm{~b}$ & $41,60 \mathrm{a}$ & 60,20 & $24,40 \mathrm{ab}$ & 31,80 & $16,80 \mathrm{~b}$ & $34,93 \mathrm{~b}$ & $34,19 \mathrm{~b}$ \\
\hline F (tratamentos) & $8,53^{* *}$ & $5,80^{*}$ & $2,98^{\mathrm{ns}}$ & $3,95^{*}$ & $1,82^{\mathrm{ns}}$ & $9,69^{* *}$ & $6,64^{* * *}$ & $10,36^{* *}$ \\
\hline d.m.s. & 15,26 & 7,90 & - & 9,11 & - & 10,50 & 11,53 & 7,08 \\
\hline \multirow[t]{2}{*}{ C.V. $(\%)$} & 20,72 & 11,46 & 16,45 & 22,84 & 22,98 & 21,96 & 15,73 & 10,77 \\
\hline & \multicolumn{8}{|c|}{ Massa da baga (g) } \\
\hline 'IAC 313' & 3,73 & 3,71 & $3,98 \mathrm{a}$ & 3,84 & 3,93 & 4,88 & 4,29 & $4,05 \mathrm{ab}$ \\
\hline 'IAC 766’ & 4,30 & 4,06 & $4,26 \mathrm{a}$ & 4,58 & 3,96 & 5,31 & 4,59 & $4,44 \mathrm{a}$ \\
\hline 'Kober 5BB' & 3,59 & 3,63 & $3,99 \mathrm{a}$ & 4,33 & 3,90 & 4,77 & 4,54 & $4,11 \mathrm{ab}$ \\
\hline ‘Traviú’ & 3,96 & 3,85 & $3,96 \mathrm{a}$ & 4,24 & 4,17 & 5,10 & 4,71 & $4,28 \mathrm{a}$ \\
\hline 'Schwarzmann' & 3,53 & 4,02 & $3,55 b$ & 3,19 & 3,29 & 4,62 & 4,23 & $3,78 b$ \\
\hline F (tratamentos) & $1,79^{\text {ns }}$ & $1,00^{\mathrm{ns}}$ & $7,74^{* *}$ & $0,85^{\mathrm{ns}}$ & $1,12^{\mathrm{ns}}$ & $1,62^{\mathrm{ns}}$ & $1,28^{\mathrm{ns}}$ & $3,88^{*}$ \\
\hline d.m.s. & - & - & 0,34 & - & - & - & - & 0,48 \\
\hline \multirow[t]{2}{*}{ C.V. (\%) } & 13,73 & 10,83 & 5,16 & 32,41 & 19,50 & 9,64 & 8,96 & 6,90 \\
\hline & \multicolumn{8}{|c|}{${ }^{\circ}$ Brix } \\
\hline 'IAC 313' & 13,41 & 13,97 & 13,61 & 14,54 & $14,60 \mathrm{~b}$ & $14,50 \mathrm{~b}$ & 14,68 & $14,18 b$ \\
\hline 'IAC 766’ & 14,48 & 14,98 & 14,50 & 15,65 & $15,60 \mathrm{ab}$ & $15,03 \mathrm{~b}$ & 14,77 & $15,00 \mathrm{ab}$ \\
\hline 'Kober 5BB' & 14,05 & 14,76 & 14,05 & 16,08 & $16,52 \mathrm{a}$ & $16,06 \mathrm{a}$ & 16,70 & $15,46 \mathrm{a}$ \\
\hline ‘Traviú' & 14,66 & 14,78 & 14,50 & 15,18 & $15,21 \mathrm{ab}$ & $15,04 \mathrm{ab}$ & 15,80 & $15,02 \mathrm{ab}$ \\
\hline 'Schwarzmann' & 14,31 & 14,45 & 14,32 & 16,19 & $15,64 \mathrm{ab}$ & $15,30 \mathrm{ab}$ & 16,74 & $15,28 \mathrm{a}$ \\
\hline $\mathrm{F}$ (tratamentos) & $2,51^{\mathrm{ns}}$ & $1,08^{\mathrm{ns}}$ & $1,18^{\mathrm{ns}}$ & $2,87^{\mathrm{ns}}$ & $4,92^{*}$ & $3,53^{*}$ & $2,26^{\mathrm{ns}}$ & $3,54^{*}$ \\
\hline d.m.s. & - & - & - & - & 1,18 & 1,03 & - & 0,97 \\
\hline C.V. $(\%)$ & 4,83 & 5,82 & 5,41 & 5,77 & 4,55 & 4,45 & 9,43 & 3,86 \\
\hline
\end{tabular}

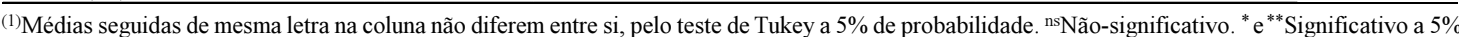
e a $1 \%$ de probabilidade, respectivamente. 
mos de reciprocidade entre copa e porta-enxerto, que envolve a absorção e translocação de água e nutrientes e os fatores endógenos de crescimento.

Assim, constatou-se, no presente trabalho, que os porta-enxertos 'IAC 766', 'IAC 313' e 'Traviú' proporcionaram melhor desempenho referente ao tamanho e massa do cacho e número de bagas por cacho, indicando, assim, que para estes três houve melhor combinação com a copa, na região de Taubaté. Nessa mesma região foi observada maior produção por planta da videira 'Niágara Rosada' sobre os porta enxertos 'IAC 766' e 'IAC 313', em relação aos porta-enxertos 'Kober 5BB' e o 'Schwarzmann', e o porta-enxerto 'Traviú' apresentou comportamento intermediário (Pauletto et al., 2001). Os porta-enxertos 'Kober 5BB' e o 'Schwarzmann' apresentaram os piores desempenhos no que se refere às características do cacho, embora tenham promovido maior teor de sólidos solúveis. Os cachos obtidos sobre estes dois porta-enxertos, além de serem menores, apresentaram-se pouco compactos, o que é uma característica que prejudica a operação de embalagem.

\section{Conclusões}

1. Os porta-enxertos 'IAC 313', 'IAC 766' e 'Traviú' proporcionam colheita de cachos de videira 'Niágara Rosada' com maior tamanho e massa, do que os porta-enxertos 'Kober 5BB' e 'Schwarzmann'.

2. Os porta-enxertos 'Kober 5BB' e 'Schwarzmann' promovem maior teor de sólidos solúveis nos frutos de videira 'Niágara Rosada' do que o porta-enxerto 'IAC 313 '.

\section{Referências}

GONÇALVES, C. A. A. Comportamento da cultivar Folha de Figo (Vitis labrusca $\mathrm{L}$.) sobre diferentes porta-enxertos de videira. Lavras : UFLA, 1996. 45 p. Dissertação de Mestrado.

HARTMANN, H. T.; KESTER, D. E. Propagación de plantas: principios y practicas. México : Continental, 1990. $760 \mathrm{p}$.

HIDALGO, L. Tratado de viticultura general. Madrid : Mundi-Prensa, 1993. 983 p.
MARTINS, P. F.; SCARANARI, J. H.; RIBEIRO, A. J. I.; TERRA, M. M.; IGUE, T.; PEREIRA M. F. Valor comparativo de cinco porta-enxertos para cultivo de uva de mesa Patrícia (IAC 871-41). In: CONGRESSO BRASILEIRO DE FRUTICULTURA, 6., 1981, Recife. Anais... Recife : Sociedade Brasileira de Fruticultura, 1981. v. 4, p. 13001310.

PAULETTO, D.; MOURÃO FILHO, F. A. A.; KLUGE, R. A.; SCARPARE FILHO, J. A. Produção e vigor da videira 'Niagara Rosada' relacionados com o porta-enxerto. Pesquisa Agropecuária Brasileira, Brasília, v. 36, n. 1, p. 115-121, jan. 2001.

PIRES, E. J. P.; MARTINS, F. P.; TERRA, M. M.; SILVA, A. C. P.; POMMER, C. V.; PASSOS, I. R. S.; COELHO, S. M. B.; RIBEIRO, I. J. A. Comportamento de cultivares IAC 116-31 e IAC 960-12 de uvas para vinho sobre diferentes porta-enxertos. In: CONGRESSO BRASILEIRO DE FRUTICULTURA, 10, 1989, Fortaleza. Anais... Fortaleza : Sociedade Brasileira de Fruticultura, 1989. p. $457-461$.

POMMER, C. V.; PASSOS, I. R. S.; TERRA, M. M.; PIRES, E. J. P. Variedades de videira para o Estado de São Paulo. Campinas : Instituto Agronômico, 1997. 59 p. (IAC. Boletim Técnico, 166).

RUHL, E. H.; CLINGELEFFER, P. R.; NICHOLAS, P. R.; CIRAMI, R. M.; McCARTHY, M. G.; WHITHING, J. R. Effect of rootstocks on berry weight and $\mathrm{pH}$, mineral content and organic acid concentrations of grapejuice of some wine varieties. Australian Journal of Experimental Agriculture, Collingwood, v. 28, n. 1, p. 119-125, 1988.

TERRA, M. M.; MARTINS, F. P.; PIRES, E. J. P.; POMMER, C. V.; PASSOS, I. R. S.; RIBEIRO, I. J. A.; COELHO, S. M. B. M.; SILVA, A. C. P. Cultivares IAC de uva Moscatel para vinho sobre diferentes porta-enxertos. In: CONGRESSO BRASILEIRO DE FRUTICULTURA, 10., 1989, Fortaleza. Anais... Fortaleza : Sociedade Brasileira de Fruticultura, 1989. p. 462-466.

TERRA, M. M.; POMMER, C. V.; ERASMO, P.; PASSOS, L. R. S.; MARTINS, F. P.; RIBEIRO, J. J. A. Comportamento de porta-enxertos para o cultivar de uva de mesa Niagara Rosada em Jundiaí, SP. In: CONGRESSO BRASILEIRO DE FRUTICULTURA, 9., 1987, Campinas. Anais... Campinas : Sociedade Brasileira de Fruticultura, 1987. p. 721-725.

ZULUAGA, A. P. Consideraciones sobre afinidad de variedades viníferas con portaenjertos americanos. Mendoza : Faculdade de Ciencias Agrarias, 1943. 34 p. (Boletín Técnico, 2). 